\title{
THE IMPACT OF THE GLOBAL SANCTIONS POLICY ON ARBITRATING BY THE INTERNATIONAL COMMERCIAL ARBITRATION COURTS: RISKS AND PROSPECTS FOR THE RUSSIAN FEDERATION
}

\author{
Svetlana Yu. Kazachenok \\ Volgograd State University, Volgograd, Russian Federation
}

\begin{abstract}
Introduction: the institution of international commercial arbitration is very popular when concluding foreign economic transactions and is a universal way of resolving the international economic disputes, but it is extremely susceptible to sanctions. In this regard, it is important to understand the impact of sanctions on the resolution of disputes in the international commercial arbitration. The purpose of this work is to study the impact of the sanctions policy on the resolution of disputes in various arbitration institutions, as well as to determine the risks and prospects of the Russian Federation in the settlement of international commercial disputes. Methods: the methodological framework for the study is a set of methods of scientific knowledge, among which the main ones are the method of analysis and the formal logical method. Results: the impact of sectoral and personal, primary and secondary sanctions on the dispute resolution in various arbitration institutions has been studied. Conclusions: the sanctions policy of the United States and the European Union significantly affects the choice of the Asian arbitration institutions as a place of arbitration and, in our opinion, can have a positive impact on the development of the Russian commercial arbitration centers.
\end{abstract}

Key words: international commercial arbitration, economic sanctions, sectoral sanctions, personal sanctions, secondary sanctions, sanctions policy.

Citation. Kazachenok S. Yu. The Impact of the Global Sanctions Policy on Arbitrating by the International Commercial Arbitration Courts: Risks and Prospects for the Russian Federation. Legal Concept, 2020, vol. 19, no. 1, pp. 24-31. (in Russian). DOI: https://doi.org/10.15688/lc.jvolsu.2020.1.3

\section{ВЛИЯНИЕ МИРОВОЙ САНКЦИОННОЙ ПОЛИТИКИ НА РАССМОТРЕНИЕ СПОРОВ МЕЖДУНАРОДНЫМИ КОММЕРЧЕСКИМИ АРБИТРАЖНЫМИ СУДАМИ: РИСКИ И ПЕРСПЕКТИВЫ ДЛЯ РОССИЙСКОЙ ФЕДЕРАЦИИ}

\author{
Светлана Юрьевна Казаченок
}

Волгоградский государственный университет, г. Волгоград, Российская Федерация 
ных, первичных и вторичных санкций на разрешение споров в различных арбитражных институтах. Выводы: санкционная политика США и стран Евросоюза значительно влияет на выбор азиатских арбитражных институтов в качестве места разрешения спора и, по нашему мнению, может оказать положительное влияние на развитие российских центров коммерческого арбитража.

Ключевые слова: международный коммерческий арбитраж, экономические санкции, секторальные санкции, персональные санкции, вторичные санкции, санкционная политика.

Цитирование. Казаченок С. Ю. Влияние мировой санкционной политики на рассмотрение споров международными коммерческими арбитражными судами: риски и перспективы для Российской Федерации // Legal Concept $=$ Правовая парадигма. -2020 . - T. 19, № 1. - C. 24-31. - DOI: https://doi.org/10.15688/lc.jvolsu.2020.1.3

\section{Введение}

Международный коммерческий арбитраж сегодня чрезвычайно востребован при заключении внешнеэкономических сделок, поскольку предоставляет существенные преимущества сторонам сделок, а именно: гибкость арбитражного процесса, элементы которого могут определять стороны; интернациональный подход, нейтральность и конфиденциальность спора.

Арбитраж считается универсальным способом разрешения международных экономических споров также потому, что, в отличие от решений государственных судов, решения коммерческих арбитражей можно признать и привести в исполнение во многих государствах, являющихся участниками НьюЙоркской конвенции о признании и приведении в исполнение иностранных арбитражных решений 1958 года.

При структурировании внешнеэкономической сделки часто встает вопрос выбора конкретного международного коммерческого арбитража для разрешения потенциального спора. Российские стороны отдают предпочтение определенным западным арбитражным институтам еще со времен «холодной войны».

Между тем арбитраж как институт не может существовать без поддержки государственных органов. Именно поэтому он так подвержен санкционному влиянию.

\section{Санкционная политика}

\section{и ее влияние на международные арбитражные учреждения}

Санкции - старейший политический инструмент, берущий свое начало в эпоху Перикла (ок. 492-429 гг. до н.э.). Принято выделять односторонние и многосторонние эконо- мические санкции. Под односторонними санкциями понимаются меры, принимаемые одним государством и (или) группой государств в отношении другого государства и (или) отдельных лиц. Такого рода санкции принимаются в виде соответствующего законодательного акта государства, имеющего иногда экстратерриториальный эффект.

Под многосторонними санкциями понимаются меры, принятые Советом Безопасности ООН в соответствии с Уставом ООН, и (или) законодательные меры государства, принятые во исполнение соответствующей резолюции Совета Безопасности ООН [11].

Несмотря на то что легитимность санкций зачастую ставится под сомнение, в XXI в. они получили широкое распространение. Так, в 2014 г. Соединенными Штатами Америки (США) и Европейским союзом (ЕС) в отношении ряда российских юридических и физических лиц и отдельных секторов экономики России были приняты односторонние экономические санкции. Данный вид санкций можно отнести к категории персональных санкций («target sanctions»), когда под их действие попадает узкий четко определенный круг лиц и (или) определенный вид деятельности [2].

Вводимые США и странами Евросоюза санкции негативно сказываются на рассмотрении споров в международных коммерческих арбитражных судах, подвластных юрисдикции этих государств. Именно поэтому российские юридические лица обратили внимание на азиатские центры арбитража [14].

Начиная с 2014 г., после того как США, Европейским союзом и рядом других стран были приняты секторальные и персональные экономические санкции в отношении российских физических и юридических лиц, российские юристы отмечают растущее количество договоров с арбитражной оговоркой, все в 
большей степени предусматривающей разрешение спора в азиатских арбитражных учреждениях [8].

Не без влияния санкционной политики популярность у российских компаний приобрели Сингапурский международный арбитражный центр (Singapore International Arbitration Centre, SIAC) и Гонконгский международный арбитражный центр (Hong Kong International Arbitration Centre, HKIAC). Это объясняется рядом преимуществ арбитражного разбирательства, к которым традиционно относят исполнимость арбитражного решения практически во всем мире, конфиденциальность, возможность выбора арбитров, универсальность процедуры разбирательства, окончательность арбитражного решения и т. п. И хотя некоторые европейские ученые выражают сомнения по поводу того, что попавшие под действие санкций контракты будут «спасены» от их влияния, если споры по ним будут проходить в азиатском арбитраже, практика показывает обратное [4].

За последние 3 года пока было лишь десять споров в Сингапурском арбитражном центре с непосредственным участием российской стороны (пять из них в 2018 г.) и шесть споров в Гонконгском арбитражном суде. При этом в статистике не учтены споры, косвенно затрагивающие интересы Российской Федерации. Для сравнения: в 2018 г. Международная торговая палата (ICC) (по всему миру, не только в Азии) рассмотрела только 16 споров с участием российской стороны.

Между тем, по статистике ICC, Сингапур занимает третье место в рейтинге самых популярных мест проведения арбитражных разбирательств, уступая лишь Лондону и Парижу.

В условиях санкций российские государственные компании обращаются в азиатские арбитражные центры, готовые сотрудничать с Россией. Так, Дубайский международный арбитражный центр на сегодняшний день является одним из самых молодых международных коммерческих арбитражей (создан в 1994 г.), однако уже сейчас там рассматривается большое количество дел. Все эти дела относятся к урегулированию споров с российскими компаниями, поскольку они активно работают в Объединенных Арабских Эмиратах.
Влияние санкций на разрешение споров с участием российской стороны и/или ее контрагентов в международных коммерческих арбитражных центрах

Российские компании столкнулись с рядом проблем в работе с европейскими арбитражными центрами. С одной стороны, они обязаны отправлять правосудие в самом широком смысле этого слова, поскольку занимаются урегулированием наиболее сложных международных споров, с другой - они являются частными, хотя и некоммерческими учреждениями и подпадают под действие юрисдикции государства, в котором они осуществляют правосудие. В основном зарегистрированные в Европейском союзе арбитражные учреждения подчиняются установлениям Евросоюза, в том числе санкционным правилам.

Практика показывает, что рассмотрение некоторых дел было необоснованно затянуто, когда одной из сторон в арбитраже была российская компания. В некоторых случаях иностранные арбитры отказались рассматривать дело компаний, включенных в санкционный список, поскольку боялись быть подверженными штрафам и наказаниям.

Кроме того, проблемы с ведением международного коммерческого арбитража возникают и в условиях неопределенности от вторичных санкций. Термин «вторичные санкции» достаточно размыт, эксперты в основном понимают под ним рестрикции, введенные в отношении иностранного субъекта за сотрудничество с объектами первичных санкций.

Так, например, в 2019 г. впервые власти США ввели санкции в отношении Египта, Китайской Народной Республики за покупку самолетов Су-35 и зенитных комплексов С-400 у России [1]. Ранее институт вторичных санкций применялся к таким государствам, как Куба или Иран, но не к российским контрагентам [11].

В связи с введением персональных и секторальных, а также вторичных санкций могут возникнуть проблемы уже на стадии назначения арбитров: если арбитр - гражданин США или ЕС, у него есть определенные ограничения в отношении арбитража субъектов под санкциями. Аналогичная ситуация с адвокатами и экспертами $[3 ; 5]$. 
Ужесточение санкционного режима оказывает существенное влияние на финансовую сторону вопроса, поскольку банковские структуры все более настороженно относятся к транзакциям, где фигурирует субъект под санкциями или существует риск его привлечения к сотрудничеству [9].

Санкции, безусловно, сказываются на работе суда. Так, Международному арбитражному суду при Международной торговой палате пришлось даже организовать специализированный департамент по работе с санкциями. В целом изменения связаны с проведением платежей, поскольку обработка финансов, внесенных стороной, попадающей под санкции, занимает более длительное время.

По мнению некоторых исследователей, временный характер вторичных санкций, их природа и преследуемая цель могут развернуть сложившуюся в мировой экономике ситуацию таким образом, что бенефициаром от накладываемых ограничений вопреки изначальной интенции будут отнюдь не европейские и американские компании.

\section{Азиатская альтернатива традиционным арбитражным центрам Европы. \\ Перспективы Российской Федерации}

В сложившейся ситуации арбитражные центры Азии, особенно Сингапура и Гонконга, представляют собой достойную альтернативу традиционным арбитражным центрам Европы [13].

В основе их успеха лежит то, что и Сингапурский, и Гонконгский международные арбитражные центры унаследовали английскую правовую систему, при этом их национальное законодательство базируется на принципах общего права и следует нормам английского права.

Стоит отметить, что и SIAC, и HKIAC предлагают получение срочных обеспечительных мер всего за неделю и ускоренное рассмотрение споров в течение шести месяцев с момента назначения арбитров, а также большой опыт и квалификацию судей. Российские компании ждут от Сингапурского и Гонконгского арбитражных центров быструю и эффективную процедуру на уровне мировых стандартов, а также сокращение издержек на процесс на 20-30 \% по сравнению с Лондоном.

Кроме того, 4 апреля 2019 г. Совет по совершенствованию третейского разбирательства при Министерстве юстиции Российской Федерации выдал разрешение администрировать споры в России Гонконгскому международному арбитражному центру, а 18 июня 2019 г. такое разрешение получил и Венский международный арбитражный центр (Vienna International Arbitral Centre, VIAC).

Это, в частности, связано с реформированием арбитражного законодательства в Российской Федерации, начавшимся еще в 2016 году. По итогам реформы деятельность по администрированию арбитража смогли продолжить только четыре арбитражные учреждения: Международный коммерческий арбитражный суд при Торгово-промышленной палате, Морская арбитражная комиссия при ТПП, Арбитражный центр при Российском союзе промышленников и предпринимателей и Российский арбитражный центр при Российском институте современного арбитража. В 2019 г. к ним присоединились Гонконгский международный арбитражный центр, Венский международный арбитражный суд и Спортивная арбитражная палата, призванная рассматривать трудовые споры спортсменов и вопросы, связанные с употреблением допинга. Подобные дела раньше рассматривались в зарубежных арбитражных институтах, в России отсутствовал свой спортивный арбитражный центр. Большинство экспертов сходятся во мнении: в результате реформы сократилось число российских арбитражных центров, но повысилось их качество.

Главная задача указанной реформы, по мнению многих юристов, - повышение респектабельности российских арбитражных учреждений. В частности, этому способствует важнейшее нововведение. Так, сейчас законодатель не просто закрепляет арбитрабельность корпоративных споров, но и вводит новые юридические категории, разделяя корпоративные споры на неарбитрабельные (споры, связанные с нотариальным удостоверением сделок с долями), условно арбитрабельные (споры по искам участников об оспаривании сделок компании) и безусловно арбитрабельные (споры, связанные с принадлежно- 
стью акций и долей российских компаний). Такая конкретика выгодна и государству, поскольку позволяет оставить часть споров в российской юрисдикции, и бизнесу, который нуждается в понятном и прозрачном механизме разрешения конфликтов.

Кроме того, начинают формироваться правила конструктивного взаимодействия между государственными судами и коммерческими арбитражами. Возможность истребовать доказательства, применять обеспечительные меры, а также использовать иные функции содействия со стороны государственных судов - все это способствует укреплению роли арбитражных институтов в качестве органов, рассматривающих коммерческие споры.

Приходится признать, что, несмотря на внесенные поправки, ожидания пока далеки от реальности: на практике возникают проблемы со взаимодействием между государственными судами и арбитражами. Например, согласно официальным данным картотеки арбитражных дел, за 2019 г. государственные суды пока не удовлетворили ни одного заявления о принятии обеспечительных мер в интересах сторон арбитражного разбирательства.

Тем не менее начало положено. Повышение привлекательности России как места арбитража невозможно без проарбитражного подхода со стороны государственных судов, и в первую очередь Верховного суда РФ.

Еще 26 декабря 2018 г. в «Обзоре практики рассмотрения судами дел, связанных с выполнением функций содействия и контроля в отношении третейских судов и международных коммерческих арбитражей», утвержденном Президиумом Верховного суда РФ, Верховный суд РФ подготовил объемные разъяснения, связанные с выполнением государственными судами функций по содействию и контролю в отношении арбитража [7]. А в Постановлении Пленума Верховного суда Российской Федерации № 53 от 10 декабря 2019 г. «О выполнении судами Российской Федерации функций содействия и контроля в отношении третейского разбирательства, международного коммерческого арбитража» Пленум Верховного суда впервые обобщил практику по вопросам взаимодействия третейского правосудия и государственного [10].
Указанные разъяснения направлены на формирование проарбитражного подхода государственных судов на уровне всех инстанций, рассматривающих данные категории дел. При условии повышения доверия к институту арбитража в России со стороны бизнеса арбитраж сможет более эффективно выполнять еще одну важную функцию - снижать нагрузку на государственные суды.

\section{Выводы}

Успешность реформирования российской арбитражной системы подтверждается исследованием Российского национального комитета Международной торговой палаты (ICC Russia) «Россия как место арбитража», проведенным в 2019 г. и завершенным международной конференцией «Россия как место разрешения споров», прошедшей 3 декабря 2019 г. в Москве.

Пятерку наиболее популярных среди возможных мест арбитража у всех респондентов составили (в порядке убывания) Арбитражный центр Торгово-промышленной палаты и промышленности Женевы, Арбитражный суд торговой палаты в Цюрихе, Международный арбитражный суд при Международной торговой палате в Париже, Международный арбитражный суд Стокгольма, Лондонский международный арбитражный суд и Международный арбитражный суд при Палате экономики Австрии в г. Вена. Москва оказалась на 6-м месте, опередив Сингапур, Гонконг и Нью-Йорк. Список замыкают Международный коммерческий арбитраж в Объединенных Арабских Эмиратах (Дубай) и Региональный центр по арбитражу в Куала-Лумпуре [6]. Однако в сравнении с аналогичным исследованием 2012 г. Москва опустилась на одну позицию.

В то же время у англоязычных респондентов указанного исследования пятерка наиболее популярных мест для проведения арбитража выглядит немного иначе: Лондон, Стокгольм, Париж, Женева/Цюрих, Вена. Москва заняла лишь 8-е место, уступив Сингапуру, Гонконгу, но обогнав Нью-Йорк. В исследовании Российского национального комитета Международной торговой палаты 2012 г. Москва заняла седьмое место. 
Думается, санкционная политика Евросоюза и США негативно влияет на выбор Российской Федерации в качестве места разрешения арбитражных споров иностранными контрагентами, однако положительно сказывается на решении российских компаний, предпочитающих российский коммерческий арбитраж иностранным институтам. Наличие высококвалифицированных специалистов, а также сравнительно невысокие затраты все чаще заставляют международные компании обратить внимание на арбитраж в России.

Введение Европейским союзом, США и некоторыми другими государствами санкций, а также вторичных санкций [12] положительно влияет на развитие азиатских центров арбитража, в частности Сингапура и Гонконга, a также дает мощный толчок развитию как Международного коммерческого арбитражного суда при Торгово-промышленной палате Российской Федерации, так и другим российским коммерческим арбитражным учреждениям, выводя Российскую Федерацию на новый уровень в качестве места разрешения коммерческих споров.

\section{СПИСОК ЛИТЕРАТУРЫ}

1. «Будут последствия»: США накажут Египет за покупку Су-35 // Газета.ru. - Электрон. текстовые дан. - Режим доступа: https://www.gazeta.ru/ army/2019/04/09/12291961.shtml (дата обращения: 05.01.2020). - Загл. с экрана.

2. Влияние антироссийских санкций на арбитраж // Арбитражная Ассоциация. - Электрон. текстовые дан. - Режим доступа: https://arbitration.ru/ press-centr/news/vliyanie-antirossiyskikh-sanktsiyna-arbitrazh/?sphrase_id=23076 (дата обращения: 05.01.2020). - Загл. с экрана.

3. Зыков, Р. О. Международный арбитраж в Швеции: правопрактика / Р. О. Зыков. - М. : Статут, 2014. $-300 \mathrm{c}$.

4. Интервью с Домиником Пелью и Михаилом Ивановым, партнерами группы международного арбитража Dentons : Колонка главного редактора. Peзультаты исследования в области развития международного арбитража // LEGAL INSIGHT. - 2019. № 1 (77).

5. Колецкий, А. Новый Регламент Арбитражного суда при Польской хозяйственной палате / А. Колецкий, П. Новачек // Международный коммерческий арбитраж. - 2008. - № 3. - С. 85-101.
6. Материалы исследования Российского национального комитета Международной торговой палаты (ICC Russia) «Россия как место арбитража» // ICC Russia. - Электрон. текстовые дан. - Режим доступа: http://www.iccwbo.ru/ (дата обращения: 05.01.2020). - Загл. с экрана.

7. Обзор практики рассмотрения судами дел, связанных с выполнением функций содействия и контроля в отношении третейских судов и международных коммерческих арбитражей : (утв. Президиумом Верховного Суда РФ 26.12.2018) // Бюллетень Верховного Суда РФ. - 2019. - № 9, сентябрь.

8. Овчаров, А. О. Особенности рассмотрения экономических споров в порядке международного арбитража / А. О. Овчаров, Н. М. Мазин // Международное публичное и частное право. - 2018. № 2. - C. 14-18.

9. Опрос Арбитражной ассоциации 2016 года: Влияние санкций на коммерческий арбитраж // Apбитражная Ассоциация. - Электрон. текстовые дан. - Режим доступа: https://arbitration.ru/upload/ medialibrary/083/2016-russian-arbitration-associationsurvey_sanctions-and-arbitration.pdf.pdf(дата обращения: 05.01.2020). - Загл. с экрана.

10. Постановление Пленума Верховного Суда РФ от 10.12.2019 № 53 «О выполнении судами Российской Федерации функций содействия и контроля в отношении третейского разбирательства, международного коммерческого арбитража» // Российская газета. - 2019. - 25 дек. (№ 291).

11. Право Европейского союза : учебник и практикум для бакалавриата и магистратуры / под ред. А. Х. Абашидзе, А. О. Иншаковой. - М. : Юрайт, 2016. $-482 \mathrm{c}$.

12. США ввели вторичные санкции за сделки с РФ. Это опасный прецедент для российского ОПК / / ТАСС. - Электрон. текстовые дан. - Режим доступа: https://tass.ru/politika/5589846 (дата обращения: 05.01.2020). - Загл. с экрана.

13. Фоков, А. П. Международный арбитражный суд ICC: возможности для России / А. П. Фоков // Международное право и международные организации. - 2015. - № 2. - С. 199-205.

14. Шляпникова, Д. Спор из избы: как повысить доверие бизнеса к российскому арбитражу / Д. Шляпникова // Forbes. - Электрон. текстовые дан. - Режим доступа: https://www.forbes.ru/biznes/ 377545-spor-iz-izby-kak-povysit-doverie-biznesa-krossiyskomu-arbitrazhu (дата обращения: 05.01.2020). Загл. с экрана.

\section{REFERENCES}

1. «Budut posledstviya»: SShA nakazhut Egipet za pokupku Su-35 [“There Will Be Consequences": 
The US Will Punish Egypt for Buying Su-35]. Gazeta.ru. URL: https://www.gazeta.ru/army/2019/04/ 09/12291961.shtml (accessed 5 January 2020).

2. Vliyanie antirossiyskikh sanktsiy na arbitrazh [Influence of Anti-Russian Sanctions on Arbitration]. Arbitrazhnaya Assotsiatsiya. URL: https://arbitration. $\mathrm{ru} / \mathrm{press}$-centr/news/vliyanie-antirossiyskikhsanktsiy-na-arbitrazh/?sphrase_id=23076 (accessed 5 January 2020).

3. Zykov R.O. Mezhdunarodnyy arbitrazh v Shvetsii: pravopraktika [International Arbitration in Sweden: Law Practice]. Moscow, Statut Publ., 2014. 300 p.

4. Intervyu s Dominikom Pelyu i Mikhailom Ivanovym, partnerami gruppy mezhdunarodnogo arbitrazha Dentons. Kolonka glavnogo redaktora. Rezultaty issledovaniya $\mathrm{v}$ oblasti razvitiya mezhdunarodnogo arbitrazha [ Interview with Dominic Pellew and Mikhail Ivanov, Partners of Dentons International Arbitration Group. Editor-in-Chief's Note. Results of the Research in the Field of the Development of International Arbitration]. LEGAL INSIGHT, 2019, no. 1 (77).

5. Koleckij A., Novachek P. Novyy Reglament Arbitrazhnogo suda pri Polskoy khozyaystvennoy palate [New Regulations of the Arbitration Court at Polish Chamber of Commerce]. Mezhdunarodnyy kommercheskiy arbitrazh, 2008, no. 3, pp. 85-101.

6. Materialy issledovaniya Rossiyskogo natsionalnogo komiteta Mezhdunarodnoy torgovoy palaty (ICC Russia) «Rossiya kak mesto arbitrazha» [Materials of the Study of the Russian National Committee of the International Chamber of Commerce (ICC Russia) "Russia as a Place of Arbitration"]. ICC Russia. URL: http://www.iccwbo.ru/ (accessed 5 January 2020).

7. Obzor praktiki rassmotreniya sudami del, svyazannykh $\mathrm{s}$ vypolneniem funktsiy sodeystviya $\mathrm{i}$ kontrolya $\mathrm{v}$ otnoshenii treteyskikh sudov $\mathrm{i}$ mezhdunarodnykh kommercheskikh arbitrazhey (utv. Prezidiumom Verkhovnogo Suda RF 26.12.2018) [Review of the Practice of Courts in Cases Related to the Performance of the Functions of Asistance and Control in Relation to Arbitration Courts and International Commercial Arbitrations (Approved by the Presidium of the Supreme Court of the Russian Federation on December 26, 2018)]. Byulleten Verkhovnogo Suda RF, 2019, no. 9, September.

8. Ovcharov A.O., Mazin N.M. Osobennosti rassmotreniya ekonomicheskikh sporov v poryadke mezhdunarodnogo arbitrazha [Features of Adjudication of Economic Disputes in the order of the International Arbitration]. Mezhdunarodnoe publichnoe i chastnoe pravo, 2018, no. 2, pp. 14-18.

9. Opros Arbitrazhnoy assotsiatsii 2016 goda: Vliyanie sanktsiy na kommercheskiy arbitrazh [Survey of the Arbitration Association in 2016: Impact of Sanctions on Commercial Arbitration]. Arbitrazhnaya Assotsiatsiya. URL: https://arbitration.ru/upload/ medialibrary/083/2016-russian-arbitration-associationsurvey_sanctions-and-arbitration.pdf.pdf (accessed 5 January 2020).

10. Postanovlenie Plenuma Verkhovnogo Suda $\mathrm{RF}$ ot 10.12 .2019 № 53 «O vypolnenii sudami Rossiyskoy Federatsii funktsiy sodeystviya i kontrolya $\mathrm{v}$ otnoshenii treteyskogo razbiratelstva, mezhdunarodnogo kommercheskogo arbitrazha» [Resolution of the Plenum of the Supreme Court of the Russian Federation Dated December 10, 2019 no. 53 "On the Performance by the Courts of the Russian Federation of the Functions of Assistance and Control in Respect of Arbitration, International Commercial Arbitration"]. Rossiyskaya gazeta, 2019, 25 Dec. (no. 291).

11. Abashidze A.H., Inshakova A.O., eds. Pravo Evropeyskogo soyuza: uchebnik i praktikum dlya bakalavriata $i$ magistratury [Law of the European Union: Textbook and Practice for Bachelor's and Master's Degree]. Moscow, Yurayt Publ., 2016. 482 p.

12. SShA vveli vtorichnye sanktsii za sdelki s RF. Eto opasnyy pretsedent dlya rossiyskogo OPK [The USA Has Imposed Secondary Sanctions for Transactions with Russia. This is a Dangerous Precedent for the Russian Defense Industry]. TASS. URL: https://tass.ru/politika/5589846 (accessed 5 January 2020).

13. Fokov A.P. Mezhdunarodnyy arbitrazhnyy sud ICC: vozmozhnosti dlya Rossii [International Arbitration Court ICC: Opportunities for Russia]. Mezhdunarodnoe pravo $i$ mezhdunarodnye organizatsii, 2015, no. 2, pp. 199-205.

14. Shlyapnikova D. Spor iz izby: kak povysit doverie biznesa $\mathrm{k}$ rossiyskomu arbitrazhu [Dispute in Public: How to Increase Business Confidence in Russian Arbitration]. Forbes. URK: https:// www.forbes.ru/biznes/377545-spor-iz-izby-kakpovysit-doverie-biznesa-k-rossiyskomu-arbitrazhu (accessed 5 January 2020). 
С.Ю. Казаченок. Влияние мировой санкционной политики на рассмотрение споров

\section{Information About the Author}

Svetlana Yu. Kazachenok, Doctor of Sciences (Jurisprudence), Honored Lawyer of the Russian Federation, Professor, Department of Civil and International Private Law, Base Department of the Southern Scientific Centre of the Russian Academy of Sciences, Volgograd State University, Prosp. Universitetsky, 100, 400062 Volgograd, Russian Federation, kazachenok@mail.ru, https://orcid.org/0000-0001-9403-820X

\section{Информация об авторе}

Светлана Юрьевна Казаченок, доктор юридических наук, заслуженный юрист Российской Федерации, профессор кафедры гражданского международного частного права (базовая кафедра ЮНЦ РАН), Волгоградский государственный университет, просп. Университетский, 100, 400062 г. Волгоград, Российская Федерация, kazachenok@mail.ru, https://orcid.org/0000-0001-9403-820X 